\title{
Temporary closure of colostomy with suture before colostomy takedown improves the postoperative outcomes
}

\author{
Wan-Hsiang Hu ${ }^{1,2} \cdot$ Ko-Chao Lee ${ }^{1} \cdot$ Kai-Lung Tsai ${ }^{1} \cdot$ Hong-Hwa Chen ${ }^{1}$
}

Accepted: 30 October 2017 / Published online: 22 November 2017

(C) The Author(s) 2017. This article is an open access publication

\begin{abstract}
Purpose Temporary loop colostomy is a common surgical procedure used to avoid complications in high-risk distal anastomosis as well as pelvic inflammation. Issues regarding postoperative outcomes of colostomy takedown have been widely discussed in the literature, wound infection especially. Temporary closure of colostomy with suture before takedown was adopted in our study, which provided excellent traction to aid mobilization of stomy and avoided stool spillage to downgrade the wound classification to "clean contamination." We aimed to determine the effects of the procedure on postoperative outcomes.

Methods This was a prospective case-control study at a single tertiary medical center. Patients presenting for elective colostomy takedown were included. Allis clamp $(n=50)$ or silk suture $(n=60)$ was applied to mobilize the colostomy, and results were compared. Operative time and wound infection rate were measured as primary postoperative outcomes. Univariate and multivariate analyses were used to demonstrate the association between the two groups and outcomes.

Results In univariate analyses, significantly shorter operative time (median $=57 \mathrm{~min}, p=0.003$ ) and lower postoperative wound infection rate $(3 \%, p=0.03)$ were noted in the group receiving silk suture. Multivariate analyses results showed that silk suture was significantly associated with both operative
\end{abstract}

Hong-Hwa Chen

ma2561@adm.cgmh.org.tw

1 Department of Colorectal Surgery, Kaohsiung Chang Gung Memorial Hospital and Chang Gung University College of Medicine, 123, Ta-Pei Rd., Niao-Sung District, Kaohsiung City 83301, Taiwan

2 Graduate Institute of Clinical Medical Science, College of Medicine, Chang Gung University, Kaohsiung, Taiwan time $(B=-8.5, p=0.01)$ and wound infection (odds ratio $=0.18, p=0.04)$.

Conclusion With the advantage of enhancing traction and decreasing contamination, the temporary closure of colostomy with suture improved takedown outcomes, including a shorter operative time and lower wound infection rate.

Keywords Colostomy · Operative time · Takedown · Wound infection

\section{Introduction}

To perform a temporary diverting colostomy is a method accepted to avoid stool from the distal bowel with anastomosis, inflammation, and trauma [1]. It is also recommended for rectal cancer patients after low-anterior resection to decrease the anastomotic leakage and reoperation rate [2-5]. Different complications were reported for patients receiving loop colostomy and ileostomy, which included ileus, dehydration, parastomal hernia, and surgical site infection [6-8].

Surgical site infection is the most common morbidity after ostomy closure, and the rate varies widely from 0 to $40 \%[1,9$, 10]. Compared to conventional primary closure, several procedures have been adopted to reduce the risk of surgical site infection [11-13]. The use of a purse-string suture for closure of surgical skin defects is found with low-infection rate [14, 15]. However, colostomy is not the focus of these studies, which has different risks and wound infection rates when compared with ileostomy [16].

Mobilization of the colostomy is a critical step in takedown. Inadequate traction and stool spillage may prolong the operative time and increase the wound infection rate. Preceding temporary closure of colostomy with silk suture enhances traction and changes the "contaminated" wound to 


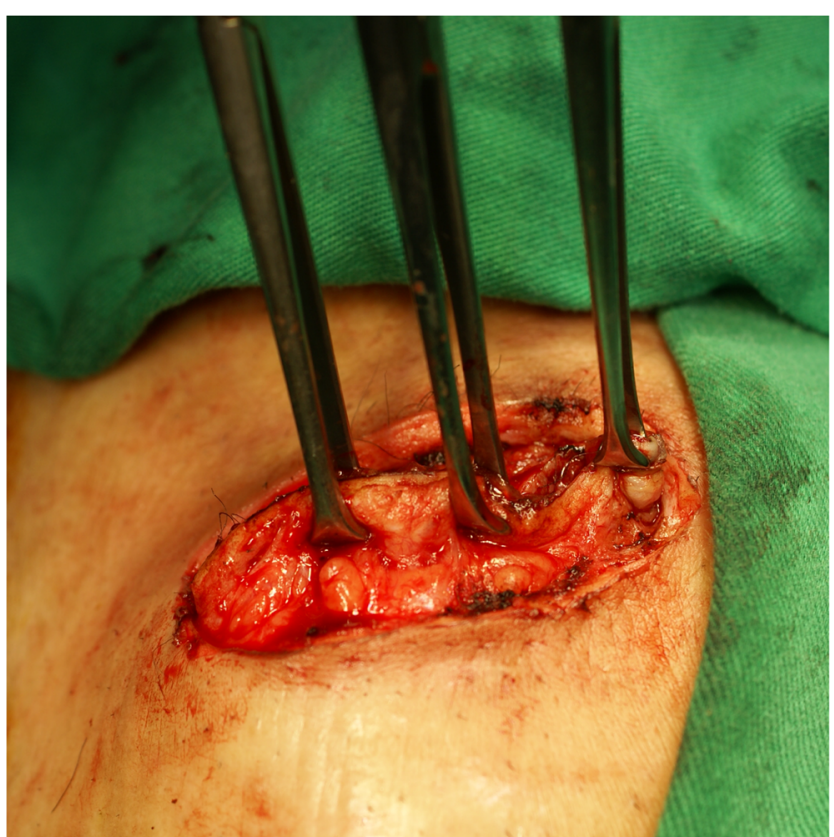

Fig. 1 Closure of colostomy with Allis clamp

"clean- contaminated" before the colostomy is mobilized. In this study, we compared two groups of patients receiving closure or not to determine the effects on postoperative outcomes.

\section{Materials and methods}

\section{Patients}

The study was approved by the Chang Gung Medial Foundation Institutional Review Board. Patients who underwent loop colostomy takedown were included in the study. Clinicopathological features of each patient were recorded, which included age, gender, body mass index (BMI), comorbidities, interval from creation of loop colostomy to closure, preoperative hemoglobin and hematocrit data, and American Society of Anesthesiologists (ASA).

\section{Operative technique}

Preoperative bowel prepares included clear liquid diet, preoperative prophylactic antibiotics (first-generation cephalosporin and fasigyn), and three-way irrigation. After incision of peristomal skin, the surgeon decided which procedure the patients were going to receive before mobilizing the colostomy. Allis tissue forceps were used to clamp the ostomy in the Clamp group (Fig. 1). In the Suture group, temporary closure of the ostomy with silk suture was performed (Fig. 2a). Povidone iodine gauze was tied on the surface of ostomy for sterilization and avoidance of stool leak (Fig. 2b). Traction provided by suture was used for further dissection (Fig. 3a and b). Mobilization, excision of ostomy edge with skin, anastomosis with absorbable suture, repair of the rectus sheath, and primary closure of wound skin were same in both groups.

\section{Outcome measurements}

Operative time and wound infection rate were primary endpoints. Operative time was measured from takedown start to takedown finish [17]. Wound infection was identified by the review of progress notes, e.g., clinical findings of localized cellulitis, need for antibiotic treatment, and/or opening of the wound $[12,18]$.

\section{Statistical analyses}

Fisher's exact test was used to determine the association between groups and categorical variables. The Mann-Whitney $U$ test and an unpaired $t$ test were computed for continuous variables. Multivariate analysis was adjusted with significant preoperative demographic and clinical factors. Multiple regression analysis and multivariate logistic regression were used to
Fig. 2 Closure of colostomy with silk suture (a) and povidone iodine gauze on the surface of ostomy (b)
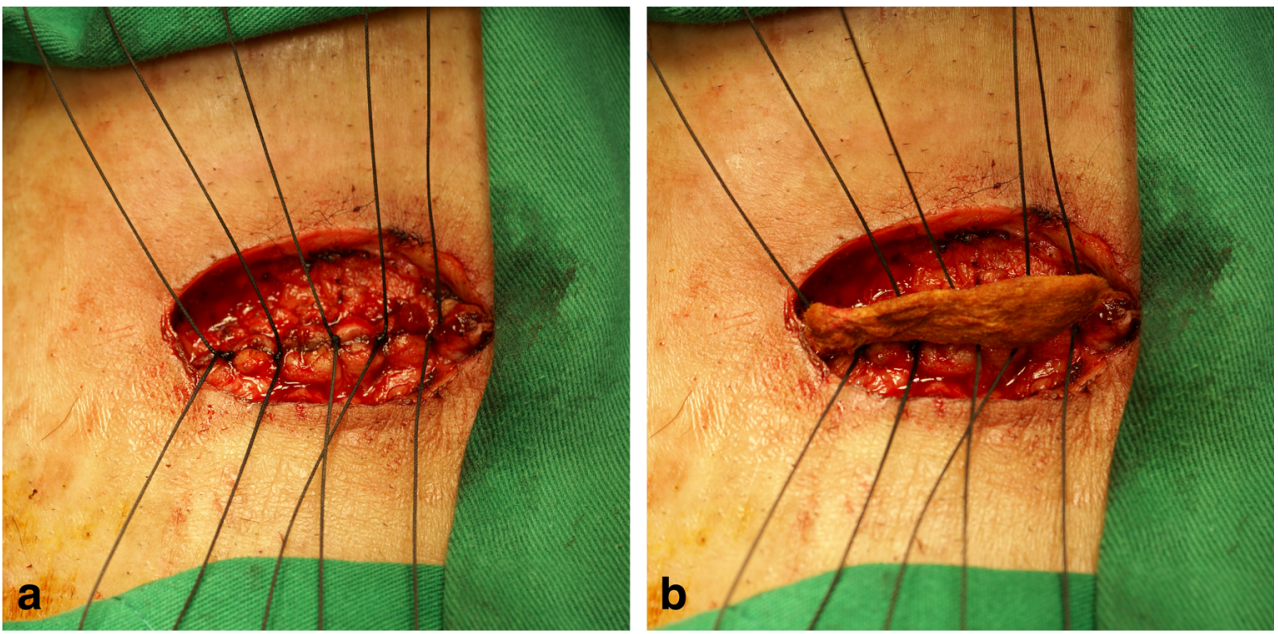
Fig. 3 Traction of silk suture (a) and further dissection (b)
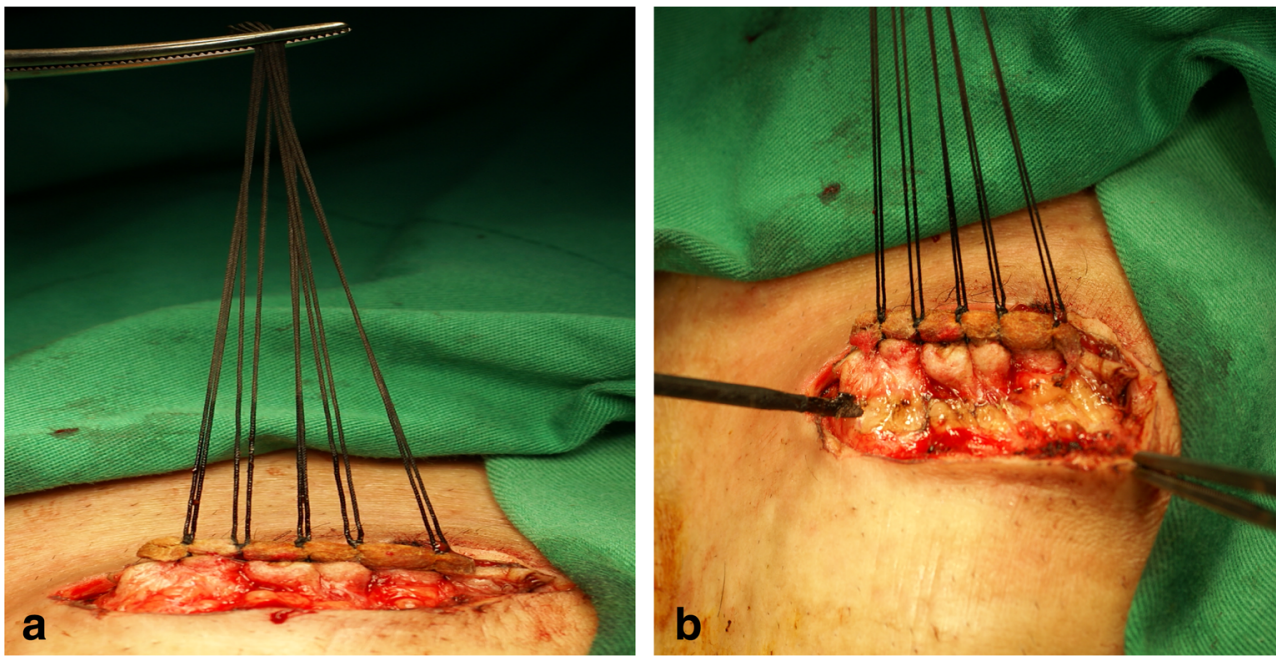

demonstrate the associations with operative time and wound infection, respectively. A $p$ value of $<0.05$ was considered significant. All analyses were performed using Prism 7 and SPSS version 24.

\section{Results}

A total of 110 patients who underwent takedown of loop colostomy were included in this study. Hand-sewn anastomosis was directly performed, and no colectomy was needed for every patient. There was no significant difference in clinical characteristics between Clamp and Suture groups (Table 1).

Operative time and wound infection rate were compared for the two groups. The study results were shown in Table 2, which demonstrated that mean operative times in Clamp and Suture groups were 69 and $57 \mathrm{~min}$, respectively, indicating significant $(p=0.003)$ (Table 2). Multiple regression analyses results and patients' clinical characteristics were also shown in

Table 1 Clinical characteristic of patients who received closure of colostomy stratified by different procedures

\begin{tabular}{llll}
\hline Characteristics & Clamp $(n=50)$ & Suture $(n=60)$ & $P$ value \\
\hline Age, year & $62(83-29)$ & $62(85-20)$ & 0.57 \\
Gender, male/female & $33 / 17$ & $41 / 19$ & 0.84 \\
Body mass index & $23.6(16.9-29.2)$ & $22.4(18.5-29.3)$ & 0.34 \\
Diabetes mellitus & 9 & 6 & 0.27 \\
Liver cirrhosis & 5 & 1 & 0.09 \\
Uremia & 1 & 0 & 0.45 \\
Interval to closure, day & $142.5(89-386)$ & $136.5(91-846)$ & 0.66 \\
Hemoglobin & $13(16.7-9.4)$ & $12.9(16.6-6.7)$ & 0.42 \\
Hematocrit & $39.1(47.7-29.6)$ & $38.3(47.9-21.6)$ & 0.24 \\
ASA (> 3) & 10 & 15 & 0.64 \\
\hline
\end{tabular}

ASA American Society of Anesthesiologists

Values of continuous variables: median (range)
Table 2, revealing that increased operative time was significantly noted for patients in the Clamp group $(B=8.5$, $p=0.01$ ).

Wound infection based on clinical findings occurred in eight patients in the Clamp group and two in the Suture group. The wound infection rate was significantly lower in the Suture group than in the Clamp group (3 vs 16\%, $p=0.03$ ) (Table 3). Escherichia coli were found in all patients with a positive culture. After adjusting for other clinical covariates, a significantly lower wound infection rate was found for patients in the Suture group (odds ratio $=0.18, p=0.04$ ) (Table 3). Patients in both groups had the same average length of hospital stay (7 days). The median length of hospital stay in uninfected patients was significantly shorter than that of the infection patients ( 6.5 vs. 12.6 days, $p<0.001)$. The average of length of wound infection treatment was 1 week. No anastomotic leakage was noted in any patients.

\section{Discussion}

Temporary closure of a colostomy with silk suture shortened the operative time and lowered the wound infection rate. We adopted the preceding procedure to improve the postoperative outcome of takedown for loop colostomy.

The operative time for takedown of loop colostomy varied. The mean operative time reported by Edwards et al. was $48 \mathrm{~min}$ [6], and the time reported by Law et al. was $51 \mathrm{~min}$ [7] in randomized clinical trials. In some retrospective studies, the median operative time ranged from 72.6 to $116 \mathrm{~min}$ [1, 11]. In two randomized trials, the average operative time was 127.2 and $116.4 \mathrm{~min}$, respectively, for loop ileostomy and colostomy $[14,15]$. It would be unfair to conclude that a takedown procedure was better based on shorter operative time alone, as there are many other confounding factors. However, the results of multivariate analyses demonstrated 
Table 2 Simple and multiple regression analysis for operative time

\begin{tabular}{|c|c|c|c|c|}
\hline \multirow[t]{2}{*}{ Variables } & \multicolumn{2}{|l|}{ Simple } & \multicolumn{2}{|l|}{ Multiple } \\
\hline & $B(95 \%$ C.I. $)$ & $P$ value & $B$ (95\% C.I. $)$ & $P$ value \\
\hline Age & $-0.14(-0.41-0.13)$ & 0.31 & - & - \\
\hline Gender, male & $5.38(2.87-13.63)$ & 0.19 & - & - \\
\hline Body mass index & $1.17(-0.13-2.47)$ & 0.07 & - & - \\
\hline Diabetes mellitus & $15.55(4.58-26.53)$ & 0.006 & $9.21(1.23-19.66)$ & 0.08 \\
\hline Liver cirrhosis & $36.07(20.3-51.84)$ & $<0.001$ & $29.09(13.1-45.04)$ & $<0.001$ \\
\hline Uremia & $-12.6(-53.7-28.3)$ & 0.54 & - & - \\
\hline Interval to closure & $-0.01(-0.02-0.04)$ & 0.56 & - & - \\
\hline Hemoglobin & $0.88(-1.36-3.13)$ & 0.43 & - & - \\
\hline Hematocrit & $0.55(-0.27-1.39)$ & 0.18 & - & - \\
\hline $\operatorname{ASA}(>3)$ & $2.66(-5.98-11.39)$ & 0.54 & - & - \\
\hline Suture group & $-11.7(-19.2--4.2)$ & 0.003 & $-8.5(-15.6--1.48)$ & 0.01 \\
\hline
\end{tabular}

$B$ coefficient, ASA American Society of Anesthesiologists that the operative time for temporary closure of colostomy was significantly decreased in our study. This might be attributed to the silk we used for suture of the colostomy. The suture silk provided us adequate and omnidirectional traction to separate and dissect the adhesive ostomy from the abdominal wall easily and quickly. However, the traction was deficient in the Clamp group. The difficulty to hold the all Allis and unequal distribution of traction force caused the edge damage of the colostomy, wound contamination and the prolonged operative time. Increased operative time is associated with higher anesthesia cost [19] and more postoperative complications [20, 21]. Further clinical trials should be designed to confirm the benefit of the surgeries with a shorter operative time.

The wound infection rate in ostomy takedown is believed to be associated with the techniques of wound closure [13, 22]. Purse-string closure was associated with fewer wound infections than primary closure in randomized controlled trials
[23]. The wound infection rates ranged from 0 to $16 \%$. However, the studies included the patients with an ileostomy $[24,25]$, which had a lower risk of wound infection than a colostomy $[1,16,26]$. Temporary suture closure preceding mobilization of the colostomy avoided stool spillage and altered the wound classification from "contaminated" to "cleancontaminated," which led to a lower wound infection rate $(3 \%)$ in our study, even although conventionally primary closure was used.

No significant difference between the two groups for the average length of hospital stay was found in our study. This finding was similar to the results of different closure techniques published previously [23, 27]. The reasons why lower wound infection rate did not seem to impact the length of hospital stay might be that the wound infection rate was too little to cause an obvious difference in hospital stay between the groups. However,
Table 3 Univariate and multivariate logistic regression analysis for postoperative wound infection

\begin{tabular}{llllll}
\hline Variables & \multicolumn{2}{l}{ Univariate } & & \multicolumn{2}{l}{ Multivariate } \\
\cline { 2 - 3 } \cline { 5 - 6 } & OR $(95 \%$ C.I. $)$ & $P$ value & & OR (95\% C.I.) & $P$ value \\
\hline Age & $1.07(1-1.14)$ & 0.03 & & $1.06(1-1.13)$ & 0.04 \\
Gender, male & $1.14(0.27-4.73)$ & 0.84 & & - & - \\
Body mass index & $1(0.8-1.24)$ & 0.98 & & - & - \\
Diabetes mellitus & $0.683(0.08-5.81)$ & 0.72 & & - \\
Liver cirrhosis & 0 & 0.99 & & - & - \\
Uremia & 0 & 1 & - & - \\
Interval to closure & $0.99(0.98-1)$ & 0.39 & & - \\
Hemoglobin & $0.98(0.67-1.43)$ & 0.94 & & - \\
Hematocrit & $1(0.88-1.17)$ & 0.79 & & - \\
ASA $>3)$ & $2.66(-5.98-11.39)$ & 0.54 & - & - \\
Suture group & $0.18(0.03-0.89)$ & 0.03 & $0.18(0.03-0.95)$ & 0.04 \\
\hline
\end{tabular}

OR odds ratio, ASA American Society of Anesthesiologists 
our study showed that hospital stay was predominantly prolonged for patients with wound infection, which was consistent with the finding in prior reports $[28,29]$. Any procedure designed to reduce wound infection rates should be applied to avoid lengthened hospital stay and the expenses derived.

$\mathrm{Li}$ et al. reported that increased BMI was a predictor of surgical site infection after a takedown procedure [22]. Mirbagheri et al. also reported that morbid obesity was significantly associated with increased risk of infection [10]. However, there was no significant difference in BMI among those with and without wound infection in our analyses. This might be attributed to the relatively low BMI our patients had, though a trend toward higher surgical site infection rates in patients with a higher BMI was found in previously published data $(p=0.051)$ [30]. Whether BMI predicts for surgical site infection after stoma reversal is still widely debated [15].

Patients with liver cirrhosis were found to have lengthened operative time in our study. Higher surgical mortality and morbidity are noted in cirrhotic patients receiving elective surgery [31] or colorectal cancer operation [32]. However, the postoperative outcomes of colostomy takedown in the patients with liver cirrhosis are scantly published. Nevertheless, bleeding stomal varices are reported to be associated with liver cirrhosis [33, 34]. Lengthened operative time in cirrhotic patients might be attributed to the time need to control the bleeding. Further studies are warranted to identify the role of liver cirrhosis in closure of colostomy.

There are several limitations to this study. First, this was not a randomized controlled trial. Second, the results for wound healing times were not shown because the exact days were not available, but the wound healing time of most patients was less than 2 weeks. Finally, the limitation in long-term follow-up made us unable to investigate the incidence and risk factors of incision hernia in temporary ostomy wound. It is still controversy if ostomy wound infection is associated significantly with incision hernia [35-37].

\section{Conclusions}

In our study, shorter operative time and decreased wound infection rate were achieved with the use of the preceding suture closure. Further prospective randomized controlled trials are needed to demonstrate the benefit of this procedure in colostomy takedown.

Acknowledgements We thank Prof. Sheng-Nan Lu, Chih-Yun Lin, Shin-Yi Chien, and the Biostatistics Center, Kaohsiung Chang Gung Memorial Hospital for statistics work.
Author contributions $\quad$ Dr. Chen, Hong-Hwa had full access to all the data in the study and takes responsibility for the integrity of the data and the accuracy of the data analysis.

Study conception and design: Chen, Hong-Hwa

Acquisition, analysis, or interpretation of data: all authors

Drafting of the manuscript: $\mathrm{Hu}$, Wan-Hsiang

Critical revision of the manuscript for important intellectual content: all authors.

Statistical analysis: Hu, Wan-Hsiang

Administrative, technical, or material support: all authors

Study supervision: all authors

\section{Compliance with ethical standards}

Disclosure The authors declare that they have no conflicts of interest.

Open Access This article is distributed under the terms of the Creative Commons Attribution 4.0 International License (http:// creativecommons.org/licenses/by/4.0/), which permits unrestricted use, distribution, and reproduction in any medium, provided you give appropriate credit to the original author(s) and the source, provide a link to the Creative Commons license, and indicate if changes were made.

\section{References}

1. Kaiser AM, Israelit S, Klaristenfeld D, Selvindoss P, Vukasin P, Ault G et al (2008) Morbidity of ostomy takedown. J Gastrointest Surg 12:437-441

2. Rullier E, Laurent C, Garrelon JL, Michel P, Saric J, Parneix M (1998) Risk factors for anastomotic leakage after resection of rectal cancer. Br J Surg 85:355-358

3. Peeters KC, Tollenaar RA, Marijnen CA, Klein Kranenbarg E, Steup WH, Wiggers T et al (2005) Risk factors for anastomotic failure after total mesorectal excision of rectal cancer. Br J Surg 92:211-216

4. Tan WS, Tang CL, Shi L, Eu KW (2009) Meta-analysis of defunctioning stomas in low anterior resection for rectal cancer. Br J Surg 96:462-472

5. Gu WL, Wu SW (2015) Meta-analysis of defunctioning stoma in low anterior resection with total mesorectal excision for rectal cancer: evidence based on thirteen studies. World J Surg Oncol 13:9

6. Edwards DP, Leppington-Clarke A, Sexton R, Heald RJ, Moran BJ (2001) Stoma-related complications are more frequent after transverse colostomy than loop ileostomy: a prospective randomized clinical trial. Br J Surg 88:360-363

7. Law WL, Chu KW, Choi HK (2002) Randomized clinical trial comparing loop ileostomy and loop transverse colostomy for faecal diversion following total mesorectal excision. Br J Surg 89:704708

8. Tilney HS, Sains PS, Lovegrove RE, Reese GE, Heriot AG, Tekkis PP (2007) Comparison of outcomes following ileostomy versus colostomy for defunctioning colorectal anastomoses. World J Surg 31:1142-1151

9. McCartan DP, Burke JP, Walsh SR, Coffey JC (2013) Purse-string approximation is superior to primary skin closure following stoma reversal: a systematic review and meta-analysis. Tech Coloproctol 17:345-351

10. Mirbagheri N, Dark J, Skinner S (2013) Factors predicting stomal wound closure infection rates. Tech Coloproctol 17:215-220

11. Mileski WJ, Rege RV, Joehl RJ, Nahrwold DL (1990) Rates of morbidity and mortality after closure of loop and end colostomy. Surg Gynecol Obstet 171:17-21 
12. Harold DM, Johnson EK, Rizzo JA, Steele SR (2010) Primary closure of stoma site wounds after ostomy takedown. Am J Surg 199:621-624

13. Li LT, Hicks SC, Davila JA, Kao LS, Berger RL, Arita NA et al (2014) Circular closure is associated with the lowest rate of surgical site infection following stoma reversal: a systematic review and multiple treatment meta-analysis. Color Dis 16:406-416

14. Camacho-Mauries D, Rodriguez-Diaz JL, Salgado-Nesme N, Gonzalez QH, Vergara-Fernandez O (2013) Randomized clinical trial of intestinal ostomy takedown comparing pursestring wound closure vs conventional closure to eliminate the risk of wound infection. Dis Colon Rectum 56:205-211

15. Lee JT, Marquez TT, Clerc D, Gie O, Demartines N, Madoff RD et al (2014) Pursestring closure of the stoma site leads to fewer wound infections: results from a multicenter randomized controlled trial. Dis Colon Rectum 57:1282-1289

16. Geng HZ, Nasier D, Liu B, Gao H, Xu YK (2015) Meta-analysis of elective surgical complications related to defunctioning loop ileostomy compared with loop colostomy after low anterior resection for rectal carcinoma. Ann R Coll Surg Eng1 97:494-501

17. Daley BJ, Cecil W, Clarke PC, Cofer JB, Guillamondegui OD (2015) How slow is too slow? Correlation of operative time to complications: an analysis from the Tennessee surgical quality collaborative. J Am Coll Surg 220:550-558

18. Liang MK, Li LT, Avellaneda A, Moffett JM, Hicks SC, Awad SS (2013) Outcomes and predictors of incisional surgical site infection in stoma reversal. JAMA Surg 148:183-189

19. Farnworth LR, Lemay DE, Wooldridge T, Mabrey JD, Blaschak MJ, DeCoster TA et al (2001) A comparison of operative times in arthroscopic ACL reconstruction between orthopaedic faculty and residents: the financial impact of orthopaedic surgical training in the operating room. Iowa Orthop J 21:31-35

20. Jackson TD, Wannares JJ, Lancaster RT, Rattner DW, Hutter MM (2011) Does speed matter? The impact of operative time on outcome in laparoscopic surgery. Surg Endosc 25:2288-2295

21. Bailey MB, Davenport DL, Vargas HD, Evers BM, McKenzie SP (2014) Longer operative time: deterioration of clinical outcomes of laparoscopic colectomy versus open colectomy. Dis Colon Rectum $57: 616-622$

22. Li LT, Brahmbhatt R, Hicks SC, Davila JA, Berger DH, Liang MK (2014) Prevalence of surgical site infection at the stoma site following four skin closure techniques: a retrospective cohort study. Dig Surg 31:73-78

23. Hsieh MC, Kuo LT, Chi CC, Huang WS, Chin CC (2015) Pursestring closure versus conventional primary closure following stoma reversal to reduce surgical site infection rate: a meta-analysis of randomized controlled trials. Dis Colon Rectum 58:808-815

24. Reid K, Pockney P, Pollitt T, Draganic B, Smith SR (2010) Randomized clinical trial of short-term outcomes following purse- string versus conventional closure of ileostomy wounds. Br J Surg 97:1511-1517

25. Dusch N, Goranova D, Herrle F, Niedergethmann M, Kienle P (2013) Randomized controlled trial: comparison of two surgical techniques for closing the wound following ileostomy closure: purse string vs direct suture. Color Dis 15:1033-1040

26. Rondelli F, Reboldi P, Rulli A, Barberini F, Guerrisi A, Izzo L et al (2009) Loop ileostomy versus loop colostomy for fecal diversion after colorectal or coloanal anastomosis: a meta-analysis. Int J Color Dis 24:479-488

27. Wada Y, Miyoshi N, Ohue M, Noura S, Fujino S, Sugimura K et al (2015) Comparison of surgical techniques for stoma closure: a retrospective study of purse-string skin closure versus conventional skin closure following ileostomy and colostomy reversal. Mol Clin Oncol 3:619-622

28. Green JW, Wenzel RP (1977) Postoperative wound infection: a controlled study of the increased duration of hospital stay and direct cost of hospitalization. Ann Surg 185:264-268

29. Mahmoud NN, Turpin RS, Yang G, Saunders WB (2009) Impact of surgical site infections on length of stay and costs in selected colorectal procedures. Surg Infect 10:539-544

30. Marquez TT, Christoforidis D, Abraham A, Madoff RD, Rothenberger DA (2010) Wound infection following stoma takedown: primary skin closure versus subcuticular purse-string suture. World J Surg 34:2877-2882

31. Csikesz NG, Nguyen LN, Tseng JF, Shah SA (2009) Nationwide volume and mortality after elective surgery in cirrhotic patients. J Am Coll Surg 208:96-103

32. Han EC, Ryoo SB, Park JW, Yi JW, HK O, Choe EK et al (2017) Oncologic and surgical outcomes in colorectal cancer patients with liver cirrhosis: a propensity-matched study. PLoS One 12:e178920

33. Spier BJ, Fayyad AA, Lucey MR, Johnson EA, Wojtowycz M, Rikkers L et al (2008) Bleeding stomal varices: case series and systematic review of the literature. Clin Gastroenterol Hepatol 6: 346-352

34. Shreiner A, Dasika NL, Sharma P (2013) Lower GI bleeding in a patient with cirrhosis and history of colorectal cancer. Peristomal varices secondary to portal hypertension. Gastroenterology 145:e3-e4

35. Guzman-Valdivia G (2008) Incisional hernia at the site of a stoma. Hernia 12:471-474

36. Schreinemacher MH, Vijgen GH, Dagnelie PC, Bloemen JG, Huizinga BF, Bouvy ND (2011) Incisional hernias in temporary stoma wounds: a cohort study. Arch Surg 146:94-99

37. Luglio G, Pendlimari R, Holubar SD, Cima RR, Nelson H (2011) Loop ileostomy reversal after colon and rectal surgery: a single institutional 5-year experience in 944 patients. Arch Surg 146: $1191-1196$ 